\title{
Editorial
}

\section{Jean-Jacques Wyndaele - The new Editor of Spinal Cord}

Spinal Cord (2006) 44, 339. doi:10.1038/sj.sc.3101927

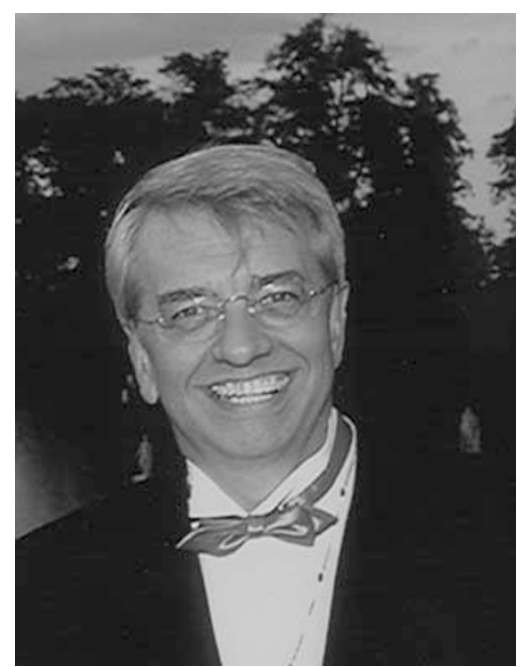

It is a pleasure to welcome Jean-Jacques Wyndaele as the new Editor of the Journal. He needs, of course, no introduction to members of the Society.

He has been a member of the Society since 1978. In 1984 he was elected to the Council and in 1991 he was elected Vice President. He was the Honorary Secretary from 1995 to 2003 and a prominent and respected member of many committees of the Society. For more than two decades he has been active in promoting the aims of the Society.

He is Chairman of the Department of Urology at the University of Antwerp, Belgium, and a Consultant Urologist to rehabilitation centres in Antwerp. In these posts, he has been continuously involved in clinical and in basic research. He is the Chairman of the laboratory for basic research in urology in the University of Antwerp and the coordinator of the University Centre for the study of the pelvic floor.

His honours are almost too numerous to list! He is a Fellow of the European Board of Urology, President of the Belgian Board of Recognition of Specialists in Urology and President of the Belgian Society for Incontinence Control among other duties.

$\mathrm{He}$ has been the invited speaker at over 100 international scientific meetings and the author of over 100 manuscripts in peer-reviewed international journals as well as writing numerous chapters in books.

It is a great personal pleasure to welcome JeanJacques as my successor as Editor of the Journal and I wish him well in this new position. There is no doubt that he will have the full support of the members of the Society, members of the Editorial Board and the Publishers of the Journal.

LS Illis Editor 